Este trabalho aprésenta algumas reflexões sobre as bases teóricoconceituais que operam na clínica em estimulação precoce, sua especialidade, suas bordas, e seu constante contato com a pediatria, a neurologia, a psicanálise, a educação e a reabilitação. $O$ terapeuta em estimulação precoce necessita da construção de uma posição interdisciplinar, o que supõe o registro da falta, os vazios, lugar em que é possível o espaço para perguntas imprescindíveis à clínica.

Estimulação precoce; filiaçäo; interdisciplinariedade

THE FOUNDATIONS AND LIMITS OF EARLY STIMULATION. REFLECTIONS

This paper presents some thoughts about the theoretical and conceptual bases that operate in clinics in early stimulation, its special$t y$, its limits, its permanent contact with pediatricians, neurology, psychoanalysis, education and rehabilitation. The therapist in early stimulation needs to construct an interdisciplinary position, which presupposes the idea of lack, privation, emptiness. Emptiness, a place where there is space for questions which are vital to the clinic.

Early stimulation; filial relationship; interdisciplinarity

\section{FUNDAMENTOS E LIMITES DA ESTIMULAÇÃO PRECOCE. ALGUMAS REFLEXÕES}

\author{
Marila Alicia Terzaghi \\ Haydée Liliana Coriat
}

Tradução: Daniela Teperman<smiles>c1ccccc1</smiles>

convite de Estilos da Clínica para integrar este número dedicado à clínica com bebês remeteu-nos imediatamente à necessidade de formular algumas pontuações a respeito da estimulação precoce e de como a temos pensado.

Desde seu nascimento - há aproximadamente trinta anos - a estimulação precoce parece situar-se em regiões de borda, de limite. E a partir desse lugar que foi recortando sua especificidade.

Limite da pediatria e da neurologia, começou a buscar em outros campos disciplinares as ferramentas teóricas e metodológicas para a abordagem da problemática do desenvolvimento infantil. Limite

Médica neurologista infantil, especialista em estimulação precoce. Membro da equipe do Centro Dra. Lydia

Coriat de Buenos Aires.

- $\square$ Licenciada em Psicologia, especialista em estimulação precoce. Membro da equipe do Centro Dra. Lydia

Coriat de Buenos Aires. 
da reabilitação, quando não há por onde introduzir o olhar particular de suas disciplinas instrumentais. Limite da educação, em momentos de construção em singular. Limite da psicanálise na clínica com bebês. Limite, recorte, especificidade que impõe nos situarmos dentro de um campo não unificado, no qual encontramos as posturas teóricas mais diversas.

Hoje, quando hoje dizemos estimulação precoce, dizemos clínica com bebês e crianças pequenas com problemas no desenvolvimento. Surgem então, de maneira quase inevitável, diversas indagações e discussões a respeito fundamentalmente do primeiro significante: "estimulação"... Poderíamos dizer intervenção, educação, atenção... eufemismos utilizados a partir de perspectivas neocondutistas, que, no entanto, não deixam de manter seu eixo no estímulo.

No entanto, parece que o termo "precoce" não cria tantos problemas e nos é de grande utilidade para situar algo no enorme campo de trabalho com bebês e crianças pequenas. Assim, permitimo-nos correr o risco de continuar usando a nomeação de estimulação precoce, na falta de uma melhor, uma vez que nos possibilita um recorte disciplinar, com certo percurso histórico, e cujo objeto conceitual específico de trabalho é o bebê.

$\mathrm{Na}$ Argentina, a estimulação precoce surgiu pelas mãos de uma neuropediatra, a dra. Lydia Coriat, que convocou profissionais de outras disciplinas a investigar o desenvolvimento infantil, e a partir disso introduziu-se no campo dos bebês com transtornos orgânicos, neurológicos, genéticos, sensoriais, de maturação e de conexão com o meio, inaugurando essa disciplina. A novidade representada pela incorporação do psicanalista a essa primeira equipe instala as bases de uma posição clínica que começa a construir-se.

Consideramos a estimulação precoce uma disciplina terapêutica cujo objeto de trabalho são os bebês que apresentam dificuldades em seu desenvolvimento.

Sustentar a clínica com bebês em estimulação precoce supõe construir uma inclinação especial no olhar. E precisamente essa inclinação especial o que instala a especificidade da estimulação precoce. Espaço singular que requer uma particular articulação de questões da estrutura com a construção e apropriação instrumental.

Grande parte dos conhecimentos das neurociências pôs em evidência a importância dos primeiros anos da vida para a construção do sistema nervoso, e os efeitos que influências do entorno têm sobre o processo maturacional. A psicanálise e a evidência clínica falam-nos das questões fundantes da constituição subjetiva que se instalam nos tempos do bebê.

A forma em que um bebê é desejado, pensado como filho, permite um olhar singular para este, olhar que, através do exercício da 
função materna, irá dizendo-lhe quem é, o que se espera dele. O olhar, o toque, a palavra, o pedido que lhe são oferecidos estarão também nessa particular etapa da vida "esculpindo" seu sistema nervoso.

"Azul chega ao tratamento aos 5 meses. Nasceu com uma importante malformação urogenital. Os médicos dizem que, se seu único rim responder, para o que terão de esperar vários meses, se poderia pensar em uma cirurgia. Azul é submetida a freqüentes estudos e controles médicos. Não há progressos em seu desenvolvimento. Solicitam aos pais uma interconsulta neurológica, na qual a estimulação precoce é indicada."

Azul é uma bela lactente que olha assustada. Quase não tem produções tônico-posturais. Seus bracinhos permanecem apertados contra o corpo e suas mãos, fechadas. Seus pais trazem todo tipo de dados médicos. Parecem especialistas em nefrologia. Logo após escutá-los olho para Azul e digo: "Você, bebê, o que pensa de toda esta confusão?" Azul sorri para mim... O pai de Azul, muito emocionado, diz: "É seu primeiro sorriso. Todos esperando pela operação salvadora, nos esquecemos dela...” Em sucessivas sessões ocorre um paulatino desdobramento maturacional (M. Terzaghi).

Quando dizemos problemas no desenvolvimento, referimo-nos àqueles que se instalam a partir do hiato possibilitado por uma patologia genética, uma lesão cerebral, uma malformação, questões que às vezes o bebê porta em seu organismo e que lançam os pais a certo registro de diferença que deixa o bebê fora de lugar. Há um deslizamento que obstaculiza a filiação.

Por ter nascido com algo que a medicina diagnostica como diferente, ou porque qualquer evento precoce altera o curso de sua maturação, e também - em algumas circunstâncias - porque os pais não podem refletir-se nele, é precisamente por motivos como esses que o bebê fica fora de lugar. Algo que se fratura dificulta seu posicionamento em um lugar de filho. O desejo de filho, que é também desejo de outro, não se pode encarnar nesse que se registra de alguma maneira como um impostor. Pode então ficar situado em diferentes lugares. Algumas vezes um diagnóstico, uma diferença, situa o bebê em uma posição de dúvida, de indagação, na qual nada pode sustentar-se, na qual há uma vacilação permanente, na qual nada se pode instalar. Então, cada gesto, cada cuidado, cada palavra, cada ordenamento torna-se difícil.

Cada ato que se dirige a um bebê na vida cotidiana parte de certa suposição de sujeito ali, antecipação necessária à constituição subjetiva. Um bebê precisa ser olhado para olhar, tocado para tocar, falado para falar...

É a partir do registro da diferença nos pais que algo se recorta, e o que se recorta é a autorização de ver alguém ali, o que vai 
além do mero sofrimento de ter recebido o Down, o lesionado como filho. Isso muitas vezes os levará a buscar um outro saber que preencha este hiato. Este é às vezes preenchido pelo "saber médico, psicológico, fonoaudiológico", que a partir do recorte específico de cada disciplina poderá ver ali o Down, a paralisia cerebral, a síndrome, o atraso, o disfuncional, ficando "isso" situado ali onde devia situar-se bebê, comprometendo-se toda possibilidade de construção em singular. É a partir de um lugar como esse, em que um diagnóstico pode determinar um destino, que encontra todo seu valor a afirmação: “...o que se antecipa em um bebê pode custar um sujeito” (Jerusalinsky, 1988).

Poderíamos pensar a partir disso como os pais, muitas vezes, tomam a bandeira da deficiência, da síndrome, da associação, como possibilidade de reconhecimento para eles, em relação ao que seu filho porta. Freqüentemente se trata de uma tentativa fracassada de filiação em relação à criança, que não só não obtém os benefícios buscados, como também deve sustentar seu diagnóstico dentro de determinados parâmetros, pois isso passa a ser imprescindível para que seus pais continuem em movimento. Girando assim os lugares, transformando a problemática que a criança porta em um lugar de "filiação" para seus pais.

É precisamente essa fratura, esse registro de diferença, esse hiato, difícil de se superar e no qual põe-se em jogo a constituição subjetiva, o que instala a clínica da estimulação precoce como lugar necessário e possível para que os pais possam ir em busca, perguntar-se acerca de seu filho. Instalando o terapeuta em um lugar de busca de um eixo no qual sustentar-se diante das vicissitudes da transferência.

Dessa forma, um especialista em estimulação precoce vê-se obrigado a perguntar-se acerca de seu objeto conceitual de trabalho e dos fundamentos de sua clínica.

"Bebê”, objeto conceitual de trabalho na clínica da estimulação precoce, construto teórico que tentamos situar no "isso", repartido entre um pequeno corpo e o discurso dos pais que o toma. Isso que todo o tempo desliza de lugar, isso que a partir da fantasmática dos pais recorta-se sobre o pequeno organismo, mas que na cena clínica de estimulação precoce é abordado não só a partir do desdobramento discursivo dessa fantasmática, mas fundamentalmente no ponto de toque dessa nesse corpinho.

Aqui o bebê está em cena, não como mera presença. A ele se dirige nossa interrogação, supondo um interlocutor. Posição que tem sentido porque os pais estão na cena clínica possibilitando o circuito transferencial no qual o bebê está imerso. Abre-se aqui um espaço de ressonâncias nos pais. 
Situar a estimulação precoce como uma disciplina instrumental tenta dar conta dessa especificidade, que se recorta do que poderia pensar-se como psicanálise com bebês, obviamente impossível (onde estaria o sujeito aqui?), e que supõe certa articulação de diferentes níveis.

Algo do diagnóstico médico, que freqüentemente portam nossos pacientes, deverá ser situado, mas adquirirá sentido em nossa clínica só a partir do momento em que se situe em relação aos efeitos nos pais. Isto é, em relação aos lugares por onde circula certa fratura que não lhes permite instalar "algo de filho aqui".

Mas em estimulação precoce é certa leitura do bebê o que permite ressituar o que dissemos anteriormente. É o que o bebê faz, a maneira de encontrar-se com os outros, sua construção tônico-postural, o que se passa com ele na construção de suas produções, a maneira singular em que determinada patologia toma seu corpo, o que nos permite ver as vicissitudes de sua constituição subjetiva.

Pensar em clínica com bebês, implica situar algo de um final que está em jogo desde o começo: um bebê deixa de sê-lo. Mudança de posição na estrutura, que possibilita uma criança, ali onde havia bebê.

A clínica com bebês é atravessada por certa temporalidade da maturação, que se aproxima em certos pontos do devir lógico da estruturação subjetiva. A inclusão do eixo diacrônico do desenvolvimento também diz respeito à especificidade de uma clínica que, sustentada em uma ética psicanalítica, não pode deixá-lo fora.

Tempo da maturação que faz obstáculos. Obstáculos que são pontos de trabalho na clínica. A "urgência" do devir maturacional, que impõe a partir do discurso médico algo da ordem do "quanto antes, melhor", pesa fortemente no trabalho com bebês. Pesa nos pais, mas também no terapeuta. É nesse ponto que interrogar a pediatria e a neurologia permite-nos sustentar uma clínica fundamentada na constituição subjetiva, a partir de onde os tempos da maturação são ressignificados.

Pensamos uma clínica da estimulação precoce em transferência, fundamentada na constituição subjetiva, utilizamos estes e outros conceitos emprestados da psicanálise, que se modificam ao ressituar-se em torno de um novo objeto conceitual de trabalho (bebê), obrigando-nos a revisar nosso recorte específico.

Encontramos na psicanálise o referencial necessário, um intelocutor permanente em relação aos problemas que a clínica nos apresenta. Interconsulta, supervisão, interdisciplina, elementos fundamentais para o trabalho dos obstáculos que se apresentam na clínica. 


\section{Dossiê}

O terapeuta em estimulação precoce necessita da construção de uma posição interdisciplinar que supõe o registro da falta, os vazios, a partir de onde se possibilita o espaço para as perguntas à equipe.

Sabemos que não temos a resposta, mas pensamos que buscá-la constrói o caminho, posição a partir da qual precisamos da equipe para continuar construindo novas perguntas que nos permitam ressituar sistematicamente a posição diante do "bebê".

\section{REFERÊNCIA BIBLIOGRÁFICA}

Jerusalinsky, A. (1988). Psicoanálisis en los problemas del desarrollo infantil. Buenos Aires: Nueva Visión.

\section{NOTA}

1 No texto original, as autoras fazem referência à possibilidade de escolha, nos países de língua espanhola, entre o uso do termo temprano (cedo) ou do termo precoz (antes de). Em língua portuguesa, a única tradução possível para ambos os termos é "precoce" (N. da T.).

Recebido em 05/2000. 